Pharmacology

\title{
Ceftriaxone pharmacokinetics by new simple and sensitive ultra-high-performance liquid chromatography method
}

\author{
Michel Leandro Campos a , Juliana de Moura Alonso ${ }^{\mathrm{b}}$, Evelin dos Santos Martins ${ }^{\text {a }}$, Jonata Augusto Oliveira ${ }^{\text {a }}$, \\ Carlos Alberto Hussni ${ }^{\text {b }}$, Rosângela Gonçalves Peccinini ${ }^{\mathrm{a}, *}$ \\ a Department of Natural Active Principles and Toxicology, School of Pharmaceutical Sciences, UNESP-Univ Estadual Paulista, Araraquara, Sao Paulo, Brazil \\ b Department of Veterinary Surgery and Anesthesiology, School of Veterinary Medicine and Animal Science, UNESP-Univ Estadual Paulista, Botucatu, Sao Paulo, Brazil
}

\section{A R T I C L E I N F O}

Article history:

Received 9 August 2016

Received in revised form 21 November 2016

Accepted 21 February 2017

Available online 27 February 2017

\section{Keywords:}

Ceftriaxone

Bioanalytical method validation

Pharmacokinetics

UHPLC

\begin{abstract}
A B S T R A C T
Ceftriaxone is a cephalosporin antibiotic with a potent antimicrobial activity and excellent penetration in most body fluids such as pleural, peritoneal, spinal and brain. These facts contribute to the application of ceftriaxone in the treatment of bacterial peritonitis, an abdominal disorder in veterinary medicine, with potential risk of death. The determination of ceftriaxone levels in plasma and peritoneal fluid may be used to assess the pharmacokinetic profile at various instances of administration and allows observing if the concentrations needed are being achieved. Therefore a method was developed and validated for the determination of ceftriaxone in plasma and peritoneal fluid which after was applied in a pharmacokinetic profile study. The bioanalytical method validation was performed according to widely acceptable experiments. Two horses were used as a model of the method applicability; ceftriaxone was intraperitoneally administered to these animals as a single dose. The plasma and peritoneal fluid analysis were performed using an UHPLC system in reverse phase chromatography mode in fully validated conditions. The methods have shown linearity between 0.49 and $500 \mu \mathrm{g} / \mathrm{mL}$ for plasma, and between 0.24 and $500 \mu \mathrm{g} / \mathrm{mL}$ for peritoneal fluid. The quantitative analysis of ceftriaxone in these matrices allows monitoring of the therapy. This method showed improved sensitivity as well as the quantitation in peritoneal fluid.
\end{abstract}

(c) 2017 Elsevier Inc. All rights reserved.

\section{Introduction}

Ceftriaxone is a cephalosporin antibiotic with a potent antimicrobial activity against the majority of Gram-negative and Gram-positive bacteria (Reiner et al., 1980). The stability against beta-lactamase activity and relatively long elimination half-life of ceftriaxone make this cephalosporin a good choice for the treatment of patients with a number of infections (Owens and Dash, 2003), including intra-abdominal infections (Yellin et al., 2002). According to Ringger et al. (1998) and Lamb et al. (2002), ceftriaxone has excellent penetration in most body fluids such as pleural, peritoneal, spinal and brain, and this fact contributes to the use of ceftriaxone in the treatment of bacterial peritonitis, or in its prophylaxis. This abdominal infection requires the drug to reach the peritoneal fluid.

Ceftriaxone is not absorbed after oral administration and thus, only used intravenously, intramuscularly (Lamb et al., 2002), or by intraperitoneal administration (Albin et al., 1986), which is particularly relevant in patients receiving peritoneal dialysis (De Vin et al., 2009).

The therapeutic drug monitoring using plasma matrix is well established (Mcwhinney et al., 2010; Verdier et al., 2011), but the determination of ceftriaxone concentration in peritoneal fluid may provide

\footnotetext{
* Corresponding author. Tel.: +55-16-33016988.

E-mail address: peccinin@fcfar.unesp.br (R.G. Peccinini).
}

additional information to ensure treatment is successful. Based upon the target pathogen in the treatment of peritonitis, reaching the desired concentration of the therapeutic drug in the peritoneal fluid is essential for treatment.

Bioanalytical methods for the quantification of ceftriaxone in plasma, urine, fat tissue, bones or cerebrospinal fluid with application in in vivo studies were available (Bowman et al., 1984; Gergs et al., 2014; Kratzer et al., 2014; Mcwhinney et al., 2010; Page-Sharp et al., 2016; Payasi et al., 2010; Ringger et al., 1996, 1998; Schleibinger et al., 2015; Steib et al., 1993; Sun et al., 2012; Verdier et al., 2011). High performance liquid chromatography (HPLC) systems with different detectors were used.

The aim of this study was to develop and validate a method for the determination of ceftriaxone in plasma and peritoneal fluid. This method was used to determine the concentration of ceftriaxone in peritoneal and plasma horse samples in order to allow comparison between those matrices.

\section{Material and methods}

\subsection{Chemical and solutions}

Ceftriaxone sodium and cefoperazone sodium (internal standard, I.S.) were purchased from Sigma-Aldrich (New Jersey, USA). The HPLC 
grade methanol and ammonium acetate were purchased from J.T. Baker (Mexico City, Mexico). The ultrapure water was obtained from a Millipore Milli-Q System and used throughout the analysis.

The stock solution of ceftriaxone was prepared in ultrapure water (Milli-Q System) at concentration $5 \mathrm{mg} / \mathrm{mL}$, while the work solution of cefoperazone (internal standard, I.S.) was prepared in ultrapure water (Milli-Q System) at concentration $1 \mathrm{mg} / \mathrm{mL}$. Both solutions were stored at $-80{ }^{\circ} \mathrm{C} \pm 2$. The ceftriaxone stock solution was used in dilutions to obtain calibration curve standards and quality control samples in plasma and peritoneal fluid.

\subsection{Chromatographic conditions and instrumentation}

The UHPLC Waters Acquity H-Class UPLC ${ }^{\circ}$ system equipped with UV-Vis detector was used. The chromatographic analysis was performed on an Acquity HSS T3 $\mathrm{C}_{18}(2.1 \times 100 \mathrm{~mm} ; 1.8 \mu \mathrm{m})$ column protected by VanGuard guard column HSS C18 $(2.1 \times 5 \mathrm{~mm} ; 1.8 \mu \mathrm{m})$, both were placed into the column oven at $40{ }^{\circ} \mathrm{C}$. The mobile phase was a mixture of methanol: ammonium acetate $20 \mathrm{mM}(21: 79, \mathrm{v} / \mathrm{v})$ in isocratic mode, with detection at $260 \mathrm{~nm}$. The flow rate was $0.4 \mathrm{~mL} /$ min and the sample injection volume was $1 \mu \mathrm{L}$. The run time was 8 minutes. The ratio of peak area of the analyte to the I.S. was used for the drug quantitation.

\subsection{Sample processing}

In order to perform the analysis, $100 \mu \mathrm{L}$ of plasma or peritoneal fluid (blank, sample, calibration standard, or quality control) plus $10 \mu \mathrm{L}$ of I.S. were deproteinized by adding $100 \mu \mathrm{L}$ of cold methanol. This procedure was followed by 1 min of vortex and centrifugation at $10640 \times \mathrm{g}$ and $4{ }^{\circ} \mathrm{C}$ for $15 \mathrm{~min}$. Then the supernatant were filtrated through PTFE syringe filters $(0.22 \mu \mathrm{m} ; 13 \mathrm{~mm})$. The final solution was transferred to maximum recovery vial and stored at $10{ }^{\circ} \mathrm{C}$ inside the sample manager until the injection.

\subsection{Bioanalytical method validation}

The validation procedure was based on the (U.S.) FDA Guidance for Industry (2001) and (Brazilian) ANVISA resolutions: 899 (2003) and 27 (2012). The evaluated parameters were linearity, precision, accuracy, selectivity, stability, carryover, recovery, and lower limit of quantitation.

For linearity, analyses of the analyte were conducted in three replicates, at seven concentration levels for plasma and eight concentration levels for peritoneal fluid. The calibration curves were generated from the ceftriaxone to I.S. peak area ratios, by least-squares linear regression and $1 / \mathrm{Y}^{2}$ weighting factor. The standard concentrations for plasma were $0.49,0.98,1.95,7.81,31.25,125$, and $500 \mu \mathrm{g} / \mathrm{ml}$, while the standard concentrations for peritoneal fluid were $0.24,0.49,0.98,1.95,7.81,31.25$, 125 , and $500 \mu \mathrm{g} / \mathrm{ml}$. ANOVA $(\mathrm{p}<0.05)$ was used to test the linearity of calibration curve.

Precision and accuracy were assessed for four concentration levels or quality control (QC), namely the lower limit of quantification (LLOQ) QC, low QC, mid QC and high QC, for which the chosen levels were $0.49,0.98,31.25$, and $400 \mu \mathrm{g} / \mathrm{ml}$, respectively for plasma, and 0.24 , $0.49,31.25$, and $400 \mu \mathrm{g} / \mathrm{ml}$, respectively for peritoneal fluid. Accuracy was evaluated as the deviation of the mean analytical result from the theoretical value, while precision was evaluated as the relative standard deviation (R.S.D.) of measurements at each level. Intra-run precision and accuracy were calculated for five replicates in the same day. On the other hand, Inter-run precision and accuracy were calculated for 15 replicate determinations at each QC level, analyzed over three nonconsecutive days. All QC samples, plasma and peritoneal fluid, were prepared on the day of analysis. The data acceptance criterion for precision was R.S.D. less than 15\%, except for LLOQ, where it should not exceed $20 \%$. For accuracy, acceptable values were $85-115 \%$ of the theoretical value, except at LLOQ, where $80-120 \%$ was acceptable as well.
The method selectivity was demonstrated by the absence of interfering peaks on the chromatogram at the retention times of ceftriaxone, when both blank (blank sample) or a blank spiked with I.S. (zero sample) were analyzed, either in plasma or peritoneal fluid.

The stability of ceftriaxone was evaluated under several storage conditions, including short-term room temperature, long-term frozen, freeze and thaw cycles and post-preparative. All stability tests were performed at the low and high QC levels for both matrices.

Ceftriaxone was considered stable if the measured analyte concentration of stored samples were $85-115 \%$ of the measured analyte concentration of fresh samples.

\subsection{Method application to a pharmacokinetic profile study}

In order to show the method application, a pharmacokinetic profile study was carried out in a $370 \mathrm{~kg}$ gelding and $350 \mathrm{~kg}$ mare. They were housed in boxes with free access to food and water. The preclinical study protocol complied with the National Institutes of Health guide for the care and use of Laboratory animals (NIH Publications no. 8023, revised 1978), and was approved by the Research Ethics Committee of the UNESP - College of Veterinary Medicine and Animal Sciences (CEUA process 105/2013).

The animals were submitted to laparoscopic procedure in order to implant a Tenckhoff peritoneal catheter, which was used for a single dose of $25 \mathrm{mg} / \mathrm{kg}$ of ceftriaxone through intraperitoneal route.

The blood and peritoneal fluid samples were collected at times of $0.5,1.0,2.0,4.0,6.0,8.0,10,12,16$, and 24 hours post-dose into tubes containing EDTA. The plasma was separated by centrifugation at $2000 \times \mathrm{g}$ for $5 \mathrm{~min}$ and stored at $-80^{\circ} \mathrm{C}$ until analysis was performed.

After analysis of the concentrations, the results were used to construct a concentration versus time profile, which were expressed as individual values for each animal. Non compartmental pharmacokinetic analysis was performed to obtain the parameters elimination half-life, volume of distribution and clearance. Statistical moments approach was used to calculate mean residence time. The extraction rate (ER) was calculated to improve the understanding of the elimination process for this animal model. It is calculated as the ratio between cardiac output $(\mathrm{CO})$ of the animal used and the obtained $\mathrm{Cl}(\mathrm{ER}=\mathrm{CO} / \mathrm{Cl})$ (Toutain and Bousquet-Mélou, 2004).

\section{Results and discussion}

\subsection{UHPLC bioanalytical method validation}

The bioanalytical method for ceftriaxone quantitation in plasma and peritoneal fluid by UHPLC was validated according to the aforementioned guides. The selectivity was found to be adequate as no interfering peaks were observed at the same retention time of the analyte in plasma or peritoneal fluid. Blank subtraction was used to enhance peak integration of ceftriaxone from peritoneal fluid. The chromatograms show ceftriaxone at 0.87 minutes and I.S at 5.50 minutes in plasma an peritoneal fluid (Fig. 1).

The calibration curves were linear from 0.49 to $500 \mu \mathrm{g} / \mathrm{ml}$ for plasma ( $y=1.007 \times-0.151, r=0.996)$, and from 0.24 to $500 \mu \mathrm{g} / \mathrm{ml}$ for peritoneal fluid ( $y=1.456 \times-0.149, r=0.992)$. The linearity tests met the acceptance criteria, with precision and accuracy in accordance with the established limits (Table 1). The established linear range of this method is superior to published ranges for both horse (Ringger et al., 1996, 1998) and human (Gergs et al., 2014; Mcwhinney et al., 2010; Page-Sharp et al., 2016; Schleibinger et al., 2015; Sun et al., 2012; Verdier et al., 2011; Zhao et al., 2014). The linear range for peritoneal fluid would be useful for the monitoring of treatment with ceftriaxone for bacterial peritonitis.

Tests of precision and accuracy were adequate according to analysis of the proposed quality controls: Low QC, Mid QC and High QC (Table 2). 

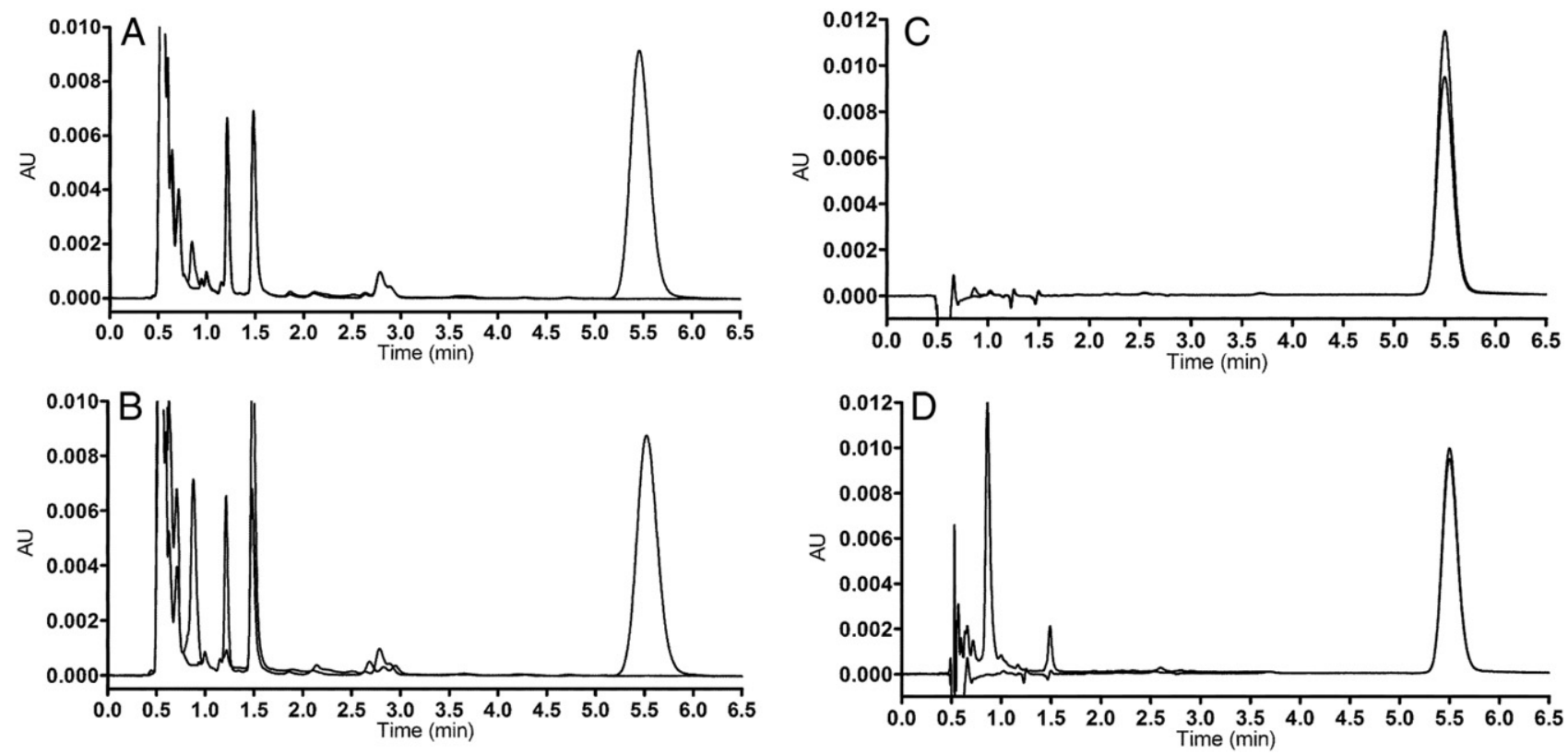

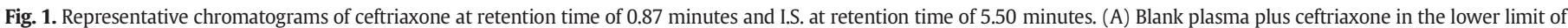
quantitation. (B) Blank plasma plus animal plasma sample at time 10 hours after ceftriaxone administration. (C) Zero peritoneal fluid plus lower limit of quantitation. (D) Zero peritoneal fluid plus peritoneal fluid sample at 8 hours after ceftriaxone administration.

Table 1

Precision and accuracy of calibration curve in horse plasma and peritoneal fluid plasma $(n=3)$.

\begin{tabular}{|c|c|c|c|c|c|}
\hline \multicolumn{3}{|l|}{ Plasma } & \multicolumn{3}{|l|}{ Peritoneal fluid } \\
\hline $\begin{array}{l}\text { Concentration } \\
(\mu \mathrm{g} / \mathrm{mL})\end{array}$ & $\begin{array}{l}\text { Precision } \\
(\%)\end{array}$ & $\begin{array}{l}\text { Accuracy } \\
(\%)\end{array}$ & $\begin{array}{l}\text { Concentration } \\
(\mu \mathrm{g} / \mathrm{mL})\end{array}$ & $\begin{array}{l}\text { Precision } \\
(\%)\end{array}$ & $\begin{array}{l}\text { Accuracy } \\
(\%)\end{array}$ \\
\hline- & - & - & 0.24 & 3.41 & 104.03 \\
\hline 0.49 & 7.20 & 102.15 & 0.49 & 10.05 & 97.35 \\
\hline 0.98 & 1.12 & 100.03 & 0.98 & 9.98 & 94.66 \\
\hline 1.95 & 6.20 & 95.52 & 1.95 & 3.08 & 102.53 \\
\hline 7.81 & 5.22 & 95.35 & 7.81 & 10.34 & 105.41 \\
\hline 31.3 & 0.70 & 102.59 & 31.3 & 6.21 & 98.78 \\
\hline 125 & 6.44 & 106.83 & 125 & 6.43 & 96.57 \\
\hline 500 & 3.62 & 103.91 & 500 & 5.29 & 104.04 \\
\hline
\end{tabular}

The lower limit of quantitation (LLOQ) was established as $0.49 \mu \mathrm{g} / \mathrm{ml}$ and $0.24 \mu \mathrm{g} / \mathrm{ml}$ for plasma and peritoneal fluid, respectively, based on the aforementioned criteria of precision and accuracy (Table 2) and their signal-to-noise ratio were higher than 5-fold. Our LLOQ is lower compared to other published methods for horse plasma (Ringger et al., 1996, 1998) and it is fully validated. Furthermore, it has better quantitation limit of several published HPLC methods for human plasma (Gergs et al., 2014; Mcwhinney et al., 2010; Page-Sharp et al., 2016; Schleibinger et al., 2015; Verdier et al., 2011; Zhao et al., 2014). Once the quantitation of ceftriaxone in peritoneal fluid can be performed through this method, that is fully validated, this is the first method to quantitate ceftriaxone in this biological matrix, which is a very important place of ceftriaxone treatment for bacterial peritonitis.

The recovery test also showed the acceptance criteria for precision and accuracy (Table 3), demonstrating that the method of processing the sample was adequate for the analysis of ceftriaxone in plasma and peritoneal fluid.

The stability assays demonstrated that prepared ceftriaxone samples were stable for 4 hours inside the auto sampler at $10^{\circ} \mathrm{C}$, and the matrix sample was stable 18 hours over the bench at room temperature, and for 14 days at $-80{ }^{\circ} \mathrm{C}$. Moreover, ceftriaxone was stable after three freeze and thaw cycles with a 24 hour interval for each thawing in both matrices (Table 4). Those evaluations are crucial, since they ensure the integrity of the drug after all storage conditions that may be necessary between the sampling and analysis.

\subsection{Application to a pharmacokinetic profile study}

Fig. 2 shows the plasma and peritoneal fluid concentration-time curves for ceftriaxone administration in two horses based on the validated bioanalytical method. The resulting concentrations allowed construction of the profiles of plasma and peritoneal fluid concentration versus time profiles of ceftriaxone. The half-life was $2.2 \mathrm{~h}$ for the gelding and $3.1 \mathrm{~h}$ for the mare. This may be explained by the difference between their volume of distribution, the results for which were $64 \mathrm{~L}$ and $97 \mathrm{~L}$, respectively. The clearances were $20.2 \mathrm{~L} / \mathrm{h}$ and $21.8 \mathrm{~L} / \mathrm{h}$ for the gelding and the mare, respectively. Based on their weight, the extraction rate was

Table 2

Precision (expressed as R.S.D.) and accuracy of quality controls of ceftriaxone plasma and peritoneal fluid.

\begin{tabular}{|c|c|c|c|c|c|c|c|c|c|}
\hline \multirow{2}{*}{\multicolumn{2}{|c|}{ Ceftriaxone Statistics }} & \multicolumn{4}{|c|}{ Plasma concentration $\mu \mathrm{g} / \mathrm{mL}$} & \multicolumn{4}{|c|}{ Peritoneal fluid concentration $\mu \mathrm{g} / \mathrm{mL}$} \\
\hline & & \multirow{2}{*}{$\begin{array}{l}0.49 \\
\text { LLOQ }\end{array}$} & \multirow{2}{*}{$\begin{array}{l}0.98 \\
\text { Low QC }\end{array}$} & \multirow{2}{*}{$\begin{array}{l}31.3 \\
\text { Mid QC }\end{array}$} & \multirow{2}{*}{$\begin{array}{l}400 \\
\text { High QC }\end{array}$} & \multirow{2}{*}{$\begin{array}{l}0.24 \\
\text { LLOQ }\end{array}$} & \multirow{2}{*}{$\begin{array}{l}0.49 \\
\text { Low QC }\end{array}$} & \multirow{2}{*}{$\begin{array}{l}31.3 \\
\text { Mid QC }\end{array}$} & \multirow{2}{*}{$\begin{array}{l}400 \\
\text { High QC }\end{array}$} \\
\hline & & & & & & & & & \\
\hline \multirow{3}{*}{ Intra-run } & $\mathrm{n}$ & 5 & 5 & 5 & 5 & 5 & 5 & 5 & 5 \\
\hline & Precision (\%) & 5.55 & 1.67 & 8.29 & 3.56 & 11.03 & 8.48 & 11.98 & 8.93 \\
\hline & Accuracy (\%) & 115.31 & 102.89 & 97.92 & 94.83 & 99.03 & 101.02 & 89.00 & 110.79 \\
\hline \multirow{3}{*}{ Inter-run } & $\mathrm{n}$ & 15 & 15 & 15 & 15 & 15 & 15 & 15 & 15 \\
\hline & Precision (\%) & 7.46 & 3.90 & 8.60 & 6.50 & 6.69 & 1.66 & 7.63 & 9.64 \\
\hline & Accuracy (\%) & 108.50 & 104.69 & 93.45 & 94.30 & 99.58 & 104.41 & 96.26 & 110.04 \\
\hline
\end{tabular}


Table 3

Recoveries at low and high QC levels for ceftriaxone in plasma and peritoneal fluid.

\begin{tabular}{llll}
\hline QC level & Statistics & Plasma & Peritoneal fluid \\
\hline \multirow{2}{*}{ Low QC } & R.S.D. (\%) & $4.5 / 9.9$ & $4.5 / 17.9$ \\
& Recovery (\%) & 107.5 & 108.1 \\
High QC & R.S.D. (\%) & $5.0 / 6.2$ & $5.0 / 13.2$ \\
Total & Recovery (\%) & 99.3 & 98.4 \\
\hline
\end{tabular}

* R.S.D. (relative standard deviation): R.S.D. of three replicates of processed QC samples/ R.S.D. of three replicates of unprocessed QC samples.

calculated as 0.016 and 0.017 , respectively, which means that the observed clearance is very low (Toutain and Bousquet-Mélou, 2004). Therefore, the clearance is not responsible for the longer half-life in the mare. The mean residence time was $3.7 \mathrm{~h}$ for the gelding and $4.7 \mathrm{~h}$ for the mare, probably reflecting their different half-lives. It is certain that a higher number of subjects would be necessary to better characterize these parameters. However, the objective of this study was to demonstrate the application of the bioanalytical method for the determination of ceftriaxone in both intended matrices.

\section{Conclusion}

As a result of this work, we developed and validated a bioanalytical method for the determination of ceftriaxone in plasma and peritoneal fluid. The method, which was applied in a pharmacokinetic profile study of ceftriaxone administered intraperitoneally in horses, demonstrated adequate sensitivity. Moreover, when compared with the published methods in the literature, most of which are for human data, our method showed certain advantages. These advantages are mainly about the ceftriaxone quantitation in peritoneal fluid, which were not found in the current survey, and the improved sensitivity, as discussed above. Finally, this is the first full validated bioanalytical method for ceftriaxone quantitation in plasma and peritoneal fluid using ultra-highperformance liquid chromatography.

\section{Declarations}

Funding: The authors thanks the sources of funding for providing financial support and the students for providing help during the sample analysis. Research was funded by São Paulo Research Foundation FAPESP (process 2011/11239-9 and process 2013/137997) and National Council for Scientific and Technological Development - CNPq. The

Table 4

Stability of ceftriaxone in plasma and peritoneal fluid under several conditions and time intervals.

\begin{tabular}{|c|c|c|c|c|}
\hline \multirow{2}{*}{ Statistics } & \multicolumn{2}{|l|}{ Plasma } & \multicolumn{2}{|c|}{ Peritoneal fluid } \\
\hline & Low QC & High QC & Low QC & High QC \\
\hline \multicolumn{5}{|c|}{ Short-term stability, $18 \mathrm{~h}$ at room temperature } \\
\hline $\mathrm{N}$ & 3 & 3 & 3 & 3 \\
\hline R.S.D.* $(\%)$ & 5.2 & 3.0 & 6.2 & 8.2 \\
\hline Accuracy (\%) & 93.78 & 99.99 & 102.65 & 112.06 \\
\hline \multicolumn{5}{|c|}{ Freeze and thaw cycles stability, 3 cycles h at $-80^{\circ} \mathrm{C}$} \\
\hline $\mathrm{N}$ & 3 & 3 & 3 & 3 \\
\hline R.S.D. ${ }^{*}(\%)$ & 2.5 & 8.0 & 1.3 & 13.8 \\
\hline Accuracy (\%) & 98.67 & 94.08 & 99.18 & 102.39 \\
\hline \multicolumn{5}{|c|}{ Long-term stability, 14 days at $-80{ }^{\circ} \mathrm{C}$} \\
\hline $\mathrm{N}$ & 3 & 3 & 3 & 3 \\
\hline R.S.D.* $(\%)$ & 5.7 & 10.7 & 2.9 & 14.7 \\
\hline Accuracy (\%) & 96.22 & 102.22 & 108.50 & 102.36 \\
\hline \multicolumn{5}{|c|}{ Post-preparative stability, $4 \mathrm{~h}$ at $10^{\circ} \mathrm{C}$} \\
\hline $\mathrm{N}$ & 3 & 3 & 3 & 3 \\
\hline R.S.D. ${ }^{*}(\%)$ & 3.1 & 5.2 & 4.0 & 8.8 \\
\hline Accuracy (\%) & 99.62 & 97.84 & 92.45 & 101.87 \\
\hline
\end{tabular}

* Relative standard deviation.

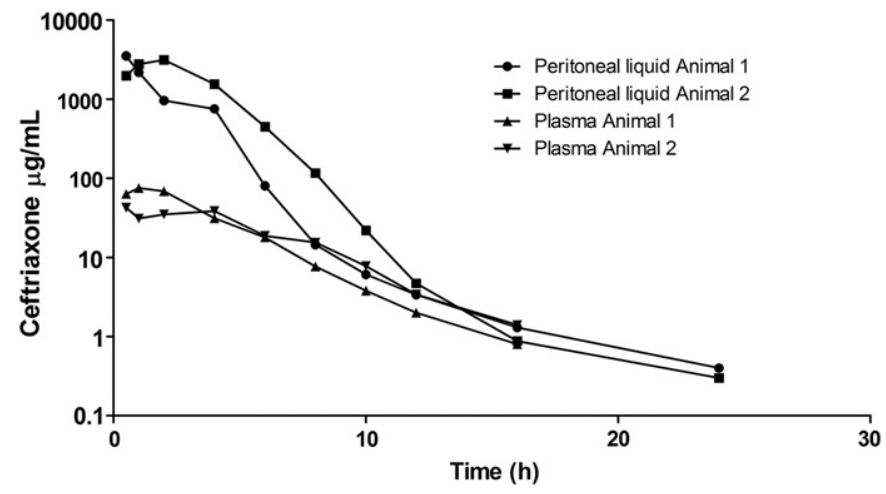

Fig. 2. Pharmacokinetic profile after single intraperitoneal dose of ceftriaxone in two horses (dose $=25 \mathrm{mg} / \mathrm{kg}$ ).

funders had no role in study design, data collection and interpretation, or the decision to submit the work for publication.

Competing Interests: The authors confirm that this article content has no conflict of interest.

Ethical Approval: The protocol for animal use was approved by the Research Ethics Committee of the UNESP - College of Veterinary Medicine and Animal Sciences (CEUA process 105/2013).

\section{References}

Albin $\mathrm{H}$, et al. Pharmacokinetics of intravenous and intraperitoneal ceftriaxone in chronic ambulatory peritoneal-dialysis. Eur J Clin Pharmacol 1986;31(4):479-83. [ISSN 00316970. Available at: $<<$ Go to ISI $>$ ://WOS:A1986F342200019>].

Bowman DB, et al. Reversed-phase high-performance liquid-chromatographic method to determine ceftriaxone in biological-fluids. J Chromatogr 1984;309(1):209-13. [ISSN 0021-9673. Available at: <<Go to ISI $>$ ://WOS:A1984TC60500027 >].

Brazil. RE n 899: Guia para validação de métodos analíticos e bioanalíticos. AGENCY, B. H. R; 2003.

Brazil. RDC N. ${ }^{\circ}$ 27. AGENCY, B. H. R; 2012.

De Vin F, Rutherford P, Faict D. Intraperitoneal administration of drugs in peritoneal dialysis patients: a review of compatibility and guidance for clinical use. Perit Dial Int 2009;29(1): 5-15. [ISSN 0896-8608. Available at: <http://www.ncbi.nlm.nih.gov/pubmed/19164246>].

FDA. Bioanalytical method validation. Rockville: U.S.: Food and Drug Administration (FDA) Center for Drug Evaluation and Research (CDER) Center for Veterinary Medicine (CVM); 2001 [25 pp.].

Gergs $U$, et al. Pharmacokinetics of ceftriaxone in plasma and bone of patients undergoing hip or knee surgery. J Pharm Pharmacol 2014;66(11):1552-8. [ISSN 0022-3573. Available at: $<<$ Go to ISI $>$ ://WOS:000343922100004>].].

Kratzer A, et al. Determination of free vancomycin, ceftriaxone, cefazolin and ertapenem in plasma by ultrafiltration: impact of experimental conditions. J Chromatogr B Analyt Technol Biomed Life Sci 2014;961:97-102. [ISSN 1570-0232. Available at: < $<$ Go to ISI $>$ ://WOS:000337863300015>].

Lamb HM, et al. Ceftriaxone - an update of its use in the management of communityacquired and nosocomial infections. Drugs 2002;62(7):1041-89. [ISSN 0012-6667. Available at: $<<$ Go to ISI $>$ :/WOS:000175694300005>].

McWhinney BC, et al. Analysis of 12 beta-lactam antibiotics in human plasma by HPLC with ultraviolet detection. J Chromatogr B Analyt Technol Biomed Life Sci 2010; 878(22):2039-43. [ISSN 1570-0232].

Owens HM, Dash AK. Ceftriaxone sodium: comprehensive profile. In: Brittain HG, editor. Profiles of drug substances, excipients and related methodology, 57, v.30. ; 2003. p. 36. [chap. 21].

Page-Sharp M, et al. Validation and application of a dried blood spot ceftriaxone assay. Antimicrob Agents Chemother 2016;60(1):14-23. [ISSN 0066-4804].

Payasi A, et al. Pharmacokinetic study of sulbactomax. J Toxicol Sci 2010;35(4):459-64 [ISSN 0388-1350. Available at: $<<$ Go to ISI $>$ ://WOS:000280679700004>].

Reiner R, et al. RO 13-9904-001, a novel potent and long-acting parenteral cephalosporin. J Antibiot 1980;33(7):783-6. [ISSN 0021-8820. Available at: $<<$ Go to ISI $>$ ://WOS: A1980KA46000022 >].

Ringger NC, et al. Pharmacokinetics of ceftriaxone in healthy horses. Equine Vet J 1996; 28(6):476-9. [ISSN 0425-1644].

Ringger NC, et al. Pharmacokinetics of ceftriaxone in neonatal foals. Equine Vet J 1998;30(2): 163-5. [ISSN 0425-1644. Available at: $<<$ Go to ISI $>$ ://WOS:000072352200014>].

Schleibinger $\mathrm{M}$, et al. Protein binding characteristics and pharmacokinetics of ceftriaxone in intensive care unit patients. Br J Clin Pharmacol 2015;80(3):525-33. [ISSN 03065251. Available at: $<<$ Go to ISI $>$ ://WOS:000360371900020 $>$ ].

Steib A, et al. Concentrations in plasma and tissue penetration of ceftriaxone and ornidazole during liver-transplantation. Antimicrob Agents Chemother 1993;37(9): 1873-6. [ISSN 0066-4804. Available at: $<<$ Go to ISI $>$ :/WOS:A1993LW35100025>].

Sun H, Wang H, Ge X. Simultaneous determination of the combined drugs of ceftriaxone sodium, metronidazole, and levofloxacin in human urine by high-performance liquid chromatography. J Clin Lab Anal 2012;26(6):486-92. [ISSN 0887-8013. Available at: $<<$ Go to ISI $>$ ://WOS:000310973200012>]. 
Toutain PL, Bousquet-Mélou A. Plasma clearance. J Vet Pharmacol Ther 2004;27(6): 415-25. [ISSN 0140-7783. Available at: < http://www.ncbi.nlm.nih.gov/pubmed/ $15601437>$ ].

Verdier M-C, et al. Simultaneous determination of 12 beta-lactam antibiotics in human plasma by high-performance liquid chromatography with UV detection: application to therapeutic drug monitoring. Antimicrob Agents Chemother 2011;55(10): 4873-9. [ISSN 0066-4804].
Yellin AE, et al. Ertapenem monotherapy versus combination therapy with ceftriaxone plus metronidazole for treatment of complicated intra-abdominal infections in adults. Int J Antimicrob Agents 2002;20(3):165-73. [ISSN 0924-8579. Available at: $<<$ Go to ISI $>$ ://WOS:000178900900002 $>$ ].

Zhao Y, et al. Systemic pharmacokinetics and cerebrospinal fluid uptake of intravenous ceftriaxone in patients with amyotrophic lateral sclerosis. J Clin Pharmacol 2014; 54(10):1180-7. [ISSN 0091-2700]. 